\title{
Characterization of biocomposite material from naturally woven coconut leaf sheath reinforced polymer composites
}

\begin{abstract}
More interest has been shown in the efficient use of natural fibers in recent years as a result of increasing concern for environmental and conservation issues. The current research investigates mechanical (tension and bending) and dimension stability (moisture absorption and thickness swelling) properties of Naturally Woven coconut tree leaf sheath (CLS) reinforced Phenol Formaldehyde (PF)/Urea Formaldehyde (UF) composites. Woven coconut leaf sheath composite were prepared in both treated and untreated forms with volume fraction of $60 \%$ of CLS and $40 \%$ of PF resin. CLS were chemically treated using $5 \%$ of $\mathrm{NaOH}$ and composites plates were prepared by using a hydraulic hot press at $140^{\circ} \mathrm{C}$. Further, these composites specimens were cut down and tested for mechanical and physical properties as per the ASTM standards. From the results in was observed that, CLS/ $\mathrm{PF}$ composites show good properties due to better bonding between fiber and the matrix (resin). This composite can sustain more load carrying capacity and resistances to moisture absorption when compared with CLS/UF composites.
\end{abstract}

Keywords: natural fiber, mechanical properties, coconut leaf sheath, polymer composites, urea formaldehyde, phenol formaldehyde
Volume 5 Issue 4 - 2019

\author{
Bharath KN, Manjunatha GB, Dileepkumar \\ SG \\ Department of Mechanical Engineering, GM Institute of \\ Technology, India
}

Correspondence: Bharath K N, GMIT, PB Road, Davangere,
Karnataka, India, Tel +9l-9844400397,

Email kn.bharath@gmail.com

Received: August 20, 2019 | Published: September 13, 2019
Abbreviations: CLS, coconut leaf sheath; PF, phenol formaldehyde resins; UF, urea formaldehyde

\section{Introduction}

Agriculture is the biggest of all industries where there is more effort than we get. Agriculture wastes are left out daily without any use. There is a lot of effort made to convert these agricultural waste by-products. Environmental concern is one of the driving forces that has led to biodegradable lingo cellulose fibers being considered for this purpose ; natural fibers have some benefits over manmade fibers, including low price, lightweight, renewable characteristics, high specific strength and modulus, and accessibility in a multitude of types worldwide and due to their excellent biocompatibility, biodegradability, mechanical properties it has been widely used in many aspects, such as medical applications and automotive parts. ${ }^{1,2}$ Considering the outstanding nature's versatility, innumerous fiber types can be combined with polymers generating a large spectrum of composite materials. ${ }^{3}$ There has been an expanding search for new materials with high performance at affordable costs in recent years. With growing environmental awareness, this search has particularly focused on eco-friendly materials, with terms such as "renewable", "recyclable", "sustainable" and "triggered biodegradable" becoming buzzwords. ${ }^{4,5}$ Tensile properties of the composite were improved by the presence of the fiber, but the untreated fibers behaved as better reinforcement than the acetylated and alkali treated fibers. The results show from literature that there was an impairment of the mechanical properties of the acetylated fibers and incompatibility of the alkalitreated fibers. Specimen treated with $1 \% \mathrm{NaOH}$ showed optimum mechanical properties but the Hydrochloric acid treatment resulted in deterioration in mechanical properties. ${ }^{6}$ Water absorption experiments were also conducted to determine saturation mass gain. Alkali treated fiber composites absorbed more water than silane treated or untreated composites. The natural fiber composites absorbed more water than the glass fiber composites. ${ }^{7-9}$

In this present work, Natural Fiber Composites are prepared using Phenol Formaldehyde and urea formaldehydes are matrix and coconut leaf sheath (CLS) as reinforcement material. The CLS fibers are treated with $\mathrm{NaOH}$ for the Alkali treatment. The main objective of this work is to compare the two matrix material (phenol formaldehyde and urea formaldehyde) on Various Properties of CLS Fiber Reinforced Polymer Composites with the treated composites. The fabrication procedure includes the Hand Layup Technique to prepare the treated (T) CLS fiber reinforced composite boards. The specimens are prepared as for the ASTM standards and various tests have been conducted to know the tensile, bending and water absorption properties of these composites.

\section{Materials and preparation of composite board}

Following materials have been used in the present work. Composite mats were prepared for two matrix materials. The chosen composite includes the following materials.

\section{Matrix Material \\ II. Phenol formaldehyde \\ III. Urea formaldehyde \\ IV. Reinforcement (CLS fiber)}

V. $\mathrm{NaOH}(1 \mathrm{~N})$ for Alkali treatment

Phenol formaldehyde resins (PF) include synthetic thermosetting resins such as obtained by the reaction of phenols with formaldehyde. Sometimes the precursors include other aldehydes or other phenol. 
Phenolic resins are mainly used in the production of circuit boards In the form of Bakelite, they are the earliest commercial synthetic resin. The building blocks for UF are Urea and Formaldehyde. Urea is synthesized from ammonia and carbon dioxide under heat, pressure and water. Urea is a whitish crystal traded in pellet form. Coconut leaf sheath is extracted from coconut tree; it acts as supporting structure to each coconut tree leaf. Coconut leaf sheath is grown simultaneously with leaf as shown in Figure 1. The coconut palm (coco's nucifera) is a member of palm family (arecaceae). Coconut leaf sheath fibers occur in mat form. The coconut tree is native to coastal areas of Southeast Asia (Malaysia, Indonesia, and Philippines), tropical pacific islands and westward to coastal India, Srilanka, East Africa, and tropical islands in the Indian Ocean. Many fibers are available in different parts of the coconut tree. The sheath is made up of an inner mat which is sandwiched between two layers of coarse fibers. Though the fibers from many parts of the coconut trees are put to use, the sheath fibers are left as huge waste.
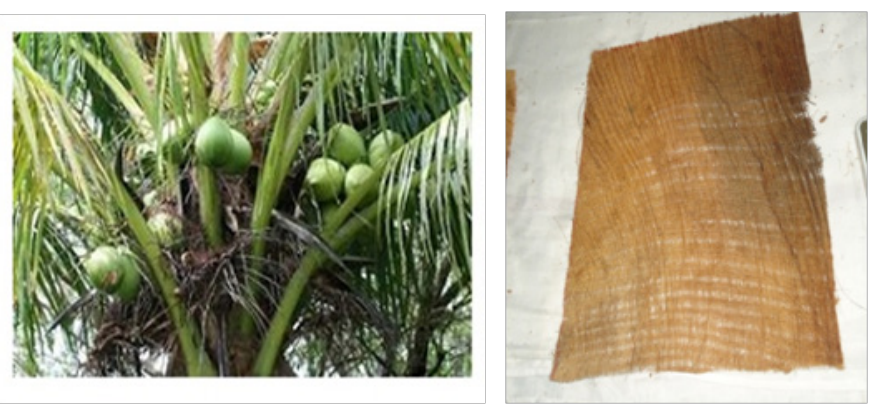

Figure I Photographs of coconut tree with leaf sheath and leaf sheath.

\section{V.I.Preparation of composite board}

The coconut fibers are extracted from coconut trees by handpicking from agricultural farms. Then coconut fibers are washed cleanly with tap water and then it is cut according to the standard dimensions. Then it is dried for a day in sunlight to remove all moisture contents present in the coconut fibers. Coconut fibers are dipped in 5\% concentration of $\mathrm{NaOH}$ of $1 \mathrm{~N}$ for 24 hours to take out unwanted materials in the fiber. The layup composite fabrication technique and stacked layers one above the other. Further the composites was pressed in a hydraulic hot press. The laminate was cured at ambient conditions for a period of about $30 \mathrm{~min}$. The laminate were prepared of a size. $200 \mathrm{mmx} 200 \mathrm{mmx} 10 \mathrm{~mm}$ as shown in Figure 2.

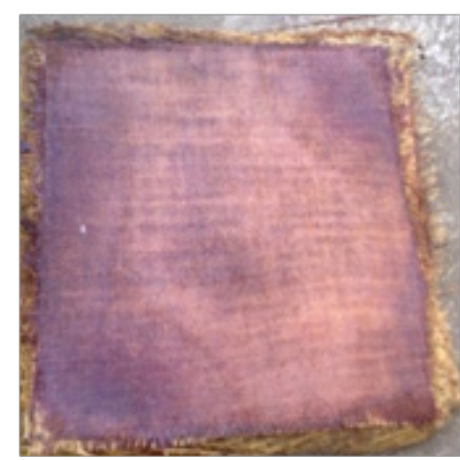

Figure 2 Composite plate.

\section{V.2. Experimentation}

V.2.1. Tensile test: According to ASTM D3039 specimens were cut from the composite board and considered for the test. ${ }^{10}$ The specimen was loaded in the universal testing machine to evaluate the strength of the composites.

V.2.2. Bending test: According to ASTM D790 composite specimens were prepared for bending test. ${ }^{11}$ The span (centre to center distance between roller supports) for each specimen is $100 \mathrm{~mm}$. The specimen is loaded at the centre of the span. The test is carried until the specimen completely fails.

V.2.3. Moisture absorption and thickness swelling test: Water is predominantly absorbed at the fiber interface and matrix. The effect of this absorbed moisture is to degrade the properties such as tensile strength. The specimens were prepared as per ASTM D-5229. ${ }^{12}$ The specimens were immersed in normal, sea water, distil water and bore water for a period of 7-10 days as shown in Figure $3 \mathrm{~A} \&$ \& $\mathrm{B}$. The moisture content in the composite is measured by the weight and thickness gain of the material in regular intervals. The percentage moisture content is expressed as the ratio of increase in weight to the weight of dry specimen. ${ }^{13}$

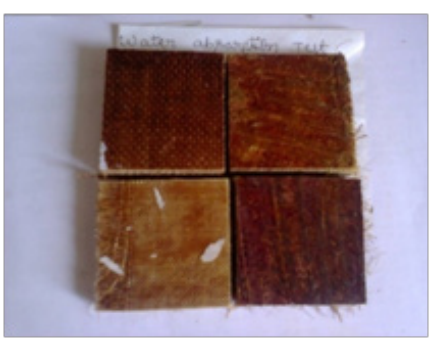

(A)

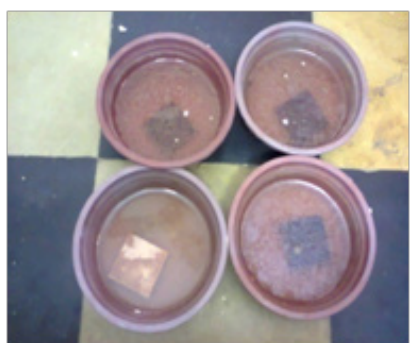

(B)
Figure 3 (A) specimen for water absorption (B) specimen dipped in different types of water.

\section{Result and discussion}

\section{I.I.Tensile test}

Figure 4 shows the load-deflection curves for tensile strength of coconut leaf sheath fiber composites. From the graph it can be seen that the load carrying capacity of PF used coconut fiber composite is greater than the UF used coconut fiber composite. It means that the strength of coconut leaf sheath fiber composite of PF is high compare to coconut leaf sheath fiber composite of UF. This was due to better adhesion properties in CLS/PF composites. ${ }^{14,15}$

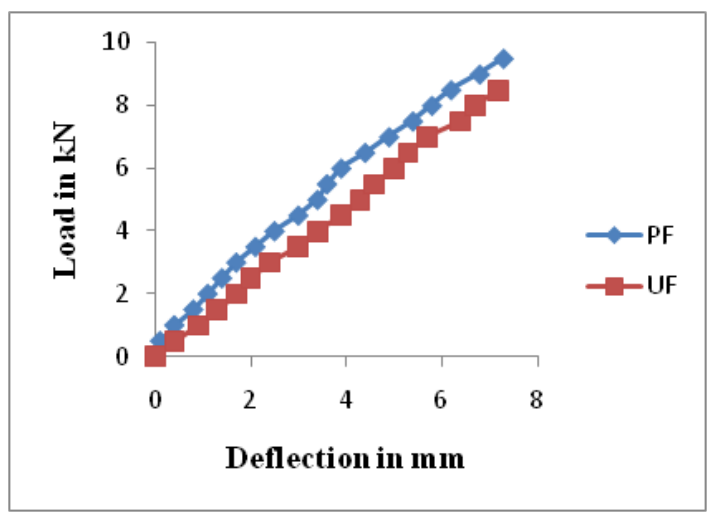

Figure 4 Shows the results of tensile test for CLS/PF and CLS/UF composites.

\section{I.2. Bending test}

From the load-deflection curves for bending strength of various 
composite plates, the composite plate of PF resin shows the maximum bending load compared to UF resin composite plate. The maximum bending strength for composite plate of $\mathrm{PF}$ is $26 \mathrm{Mpa}$ and that of UF composition composite plate is $24 \mathrm{Mpa}$. Due to both tension and compression stresses act on a bending specimen, it was found that CLS/UF composite specimens were failed due to delamination (Figure 5). ${ }^{16}$

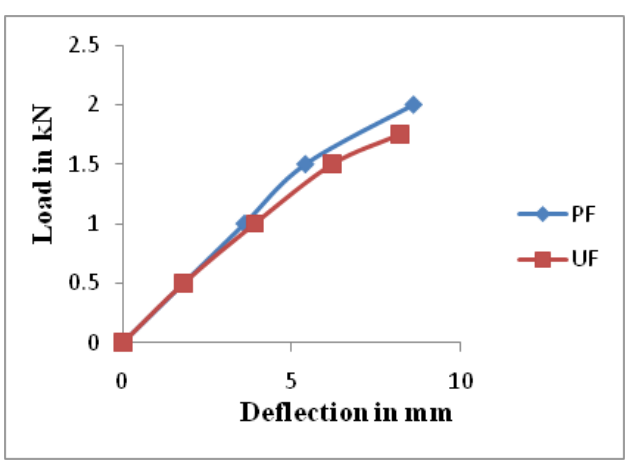

Figure 5 Shows the results of bending test for CLS/PF and CLS/UF composites.

\section{I.3. Moisture absorption test}

Consider in the moisture absorption test on above graphs (Figure 6-9) as shows the \% weight of composite v/s No. of days curves for coconut leaf sheath fiber composite plates for Normal water, Bore water, Distill water and sea water. The percentage of moisture content increases with increase in no of days Later the moisture absorption becomes almost constant after 9-10days. This is an indication of saturation. Moisture absorption of CLS/PF used plate is less compare CLS/UF. The above graph shows that the fibers reinforced with UF composite have more affinity towards distill water bore water and normal water.

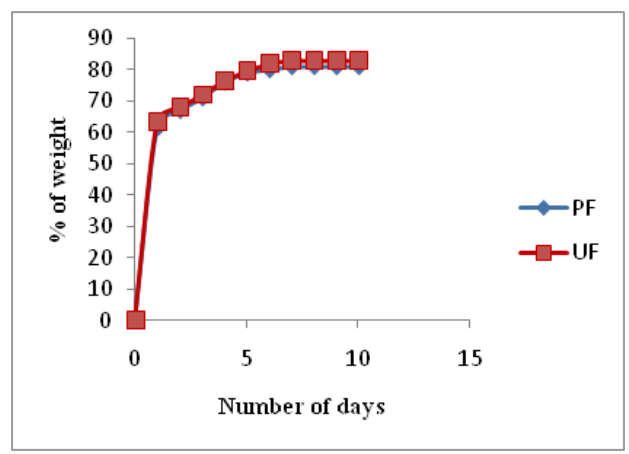

Figure $6 \%$ of Weight v/s number of days of normal water.

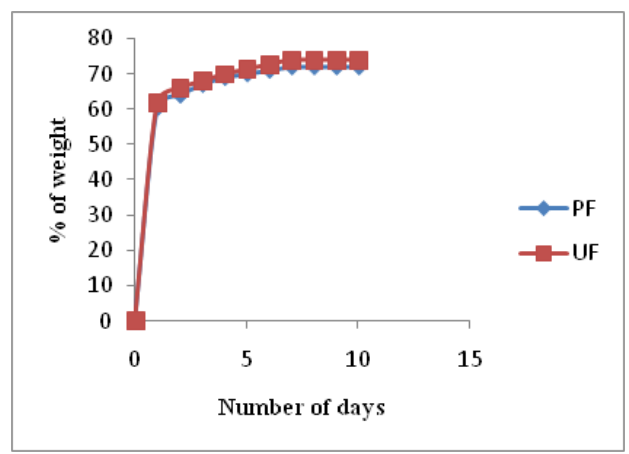

Figure $7 \%$ of Weight $v / s$ number of days of sea water.

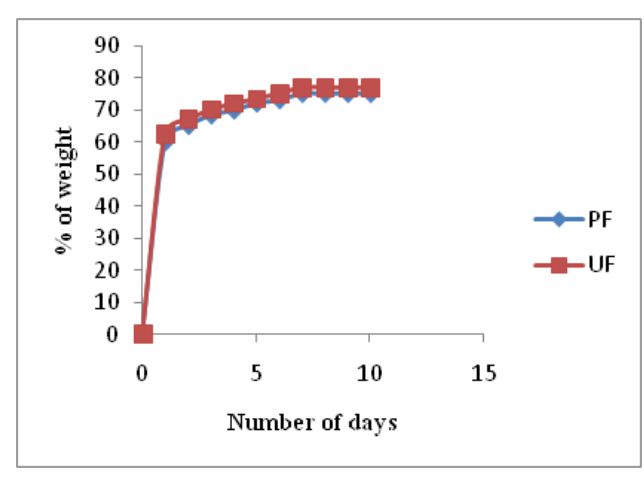

Figure $8 \%$ of Weight v/s number of days of bore water.

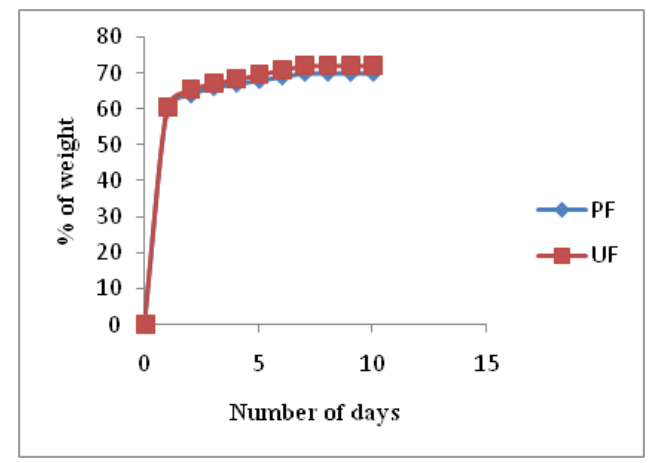

Figure $9 \%$ of Weight $v / s$ number of days of distill water.

\section{I.4. Swelling test}

In the swelling test on above graphs (Figure 10-13) as shows the thickness swelling \% of composite $\mathrm{v} / \mathrm{s}$ No. of days curves for coconut leaf sheath fiber composite plates. For Normal water, bore water, Distill water and sea water. The percentage of thickness increases with increase in no of days, Later the increasing thickness and attains saturation after 9-10 days. Thickness of swelling of PF used plate is less compare UF used plate for coconut leaf sheath fiber composite. The results indicate that thickness swelling of the composites increases due to increase in the percentage of water absorption of the composites and saturates after 9-10 days in both CLS/PF and CLS/ UF composites. ${ }^{17}$

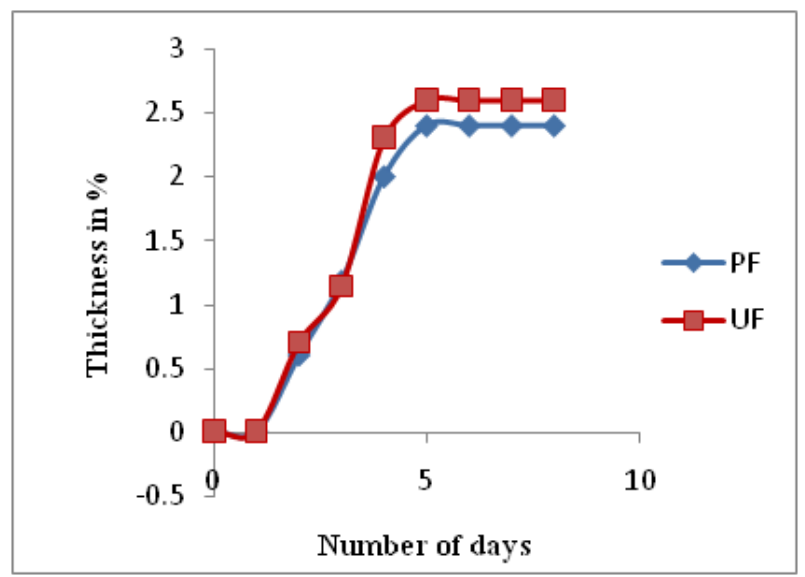

Figure 10 Thickness swelling \% v/s number of days of normal water. 


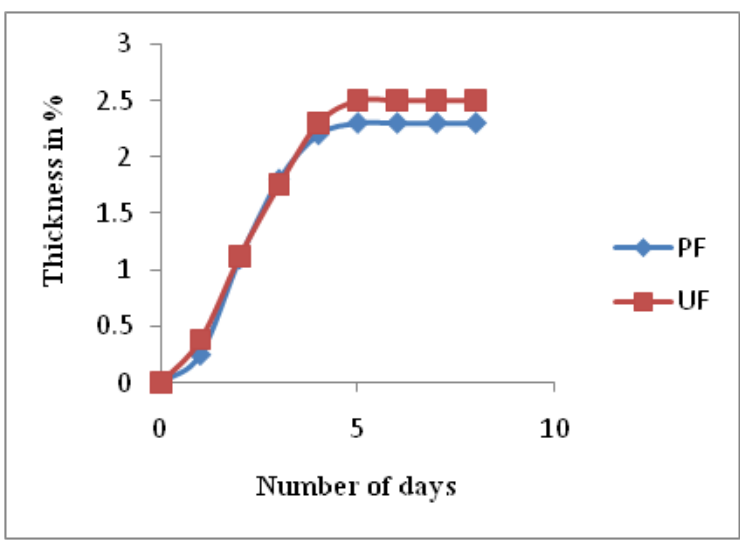

Figure I I Thickness swelling \% v/s number of days of sea water.

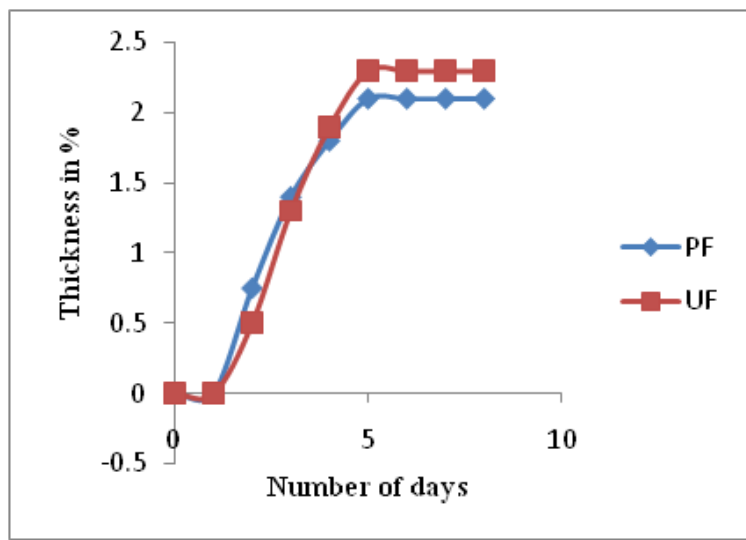

Figure 12 Thickness swelling $\% \mathrm{v} / \mathrm{s}$ number of days of bore water.

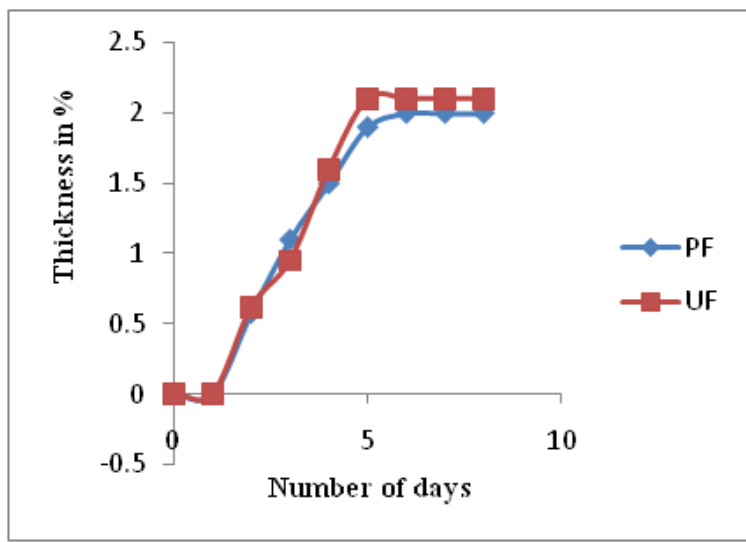

Figure 13 Thickness swelling $\% \mathrm{v} / \mathrm{s}$ numbers of days of distill water.

\section{Conclusion}

Tensile, bending, moisture absorption and thickness swelling of natural fiber CLS reinforced PF and UF composites have been experimentally evaluated. CLS fibers treated with $\mathrm{NaOH}$ solution show significant improvement for adhesion between fiber and matrix. Tensile strength of the specimen with CLS/PF shown greater value compared to CLS/UF specimen of the laminate due to better interfacial bonding between fiber and matrix. The bending strength of the specimen with CLS/PF specimen shown greater value compared to CLS/UF specimen. CLS/UF composites under testing failed due to delamination. The weight and thickness of the composites increases due to increase in percentage of water absorption of the CLS/PF\& CLS/UF composite plates. Moisture absorption of CLS/PF used specimen is less absorption compare to CLS/UF used specimen. Overall comparison between the properties of CLS/PF and CLS/ UF composite plates, all the laminates revealed that the PF used coconut leaf sheath fiber composite is the optimum combination with a good balance between the properties. PF used coconut leaf sheath fiber composite may find applications in packaging and electronics applications.

\section{Funding details}

This work is supported by Vision Group on Science and Technology, Govt. of Karnataka under the Seed money to Young Scientist for research program.

\section{Acknowledgements}

None.

\section{Conflict of interests}

Authors declare that there is no conflict of interest.

\section{References}

1. Manavendra G, Kumarappa S, Mohan Kumar GC, et al. Experimental Investigation of Thermal Properties of Areca Fiber Reinforced Phenol Formaldehyde Composites. Jour of Adv Mat. 2011;49:87-93.

2. Mansour Rokbi, Hocine Osmani, Abdellatif Imad et al. Effect of Chemical treatment on Flexure Properties of Natural Fiber-reinforced Polyester Composite. Procedia Eng. 2011;10:2092-2097.

3. Mwaikambo LY. Mechanical properties of alkali treated plant fibers and their potential as reinforcement materials. I. hemp fibers. J MATER SCI. 2006;41(8):2483-2496.

4. Srinivasa CV, Bharath KN. Water Absorption behaviour of Areca Fiber Reinforced Polymer Composites. Int Jour of Mat and Biomat App. 2012;2:12-14

5. Harsha HM, Murugesh MC, Bharath KN. Influence of Filler Materials on Pinned Joints of Woven Glass Fiber Reinforced Epoxy Composites. Jour of Comp and Biodegra Poly. 2013;1:47-55.

6. Sgriccia N, Hawley MC, Misra M. Characterization of natural fiber surfaces and natural fiber composites. Comp Part A. 2008;39:1632-1637.

7. Ahmad Alawar, Ahmantd M Hamed, Khalifa Al-Kaabi. Characterization of treated date palm tree fiber as composite reinforceme. Comp Part B. 2009;40:601-606.

8. Axel Nechwatal, Klaus-Peter Mieck, Thomas Reubmann. Developments in the characterization of natural fiber properties and in the use of natural fibers for composites. Comp Sci and Tech. 2003;63:1273-1279.

9. Andrzej K Bledzkia, Abdullah A Mamuna, Jürgen Volk. Barley husk and coconut shell reinforced polypropylene composites: The effect of fiber physical, chemical and surface properties. Comp Sci and Tech. 2010;70:840-846.

10. Annual book of ASTM standards. ASTM D-3039 standard test methods for tensile properties of polymer matrix composite material.

11. Annual book of ASTM standards. ASTM D-790 Standard Test Methods for Flexural Properties of Unreinforced and Reinforced Plastics and Electrical Insulating Materials. 
12. Annual book of ASTM standards. ASTM D-5229 standard test methods for moisture absorption of plastics.

13. Bharath KN, Sanjay MR, Mohammad Jawaid, et al. Effect of stacking sequence on properties of coconut leaf sheath/jute/ E-glass reinforced phenol formaldehyde hybrid composites. Jour of Indus Tex. 2019;49:3-32.

14. Indran, Edwin Raj R, Sreenivasan VS. Characterization of new natural cellulosic fiber from Cissusquadrangularis root. Carbo Poly. 2014;110:423-429.
15. Indran, Edwin Raj R. Characterization of new natural cellulosic fiber from Cissusquadrangularis stem. Carbo Poly 2015;117:392-399.

16. Obi Reddy K, Sivamohan Reddy G, Uma Maheswari, et al. Structural characterization of coconut tree leaf sheath fiber reinforcement. Jour Forestry Res. 2010;21:53-58.

17. Bharath KN, Swamy RP, Mohan Kumar GC. Thickness Swelling Behaviour of Hybrid Natural Fiber Reinforced UF Composites. Jour of Purity Uti Reac and Environ. 2012;1:517-524. 